\title{
Postoperative immunosuppression cascade and immunotherapy using lymphokine-activated killer cells for patients with esophageal cancer: Possible application for compensatory anti-inflammatory response syndrome
}

\author{
YOSHIYUKI YAMAGUCHI, JUN HIHARA, KATSUJI HIRONAKA, AKIKO OHSHITA, RIKI OKITA, \\ MAKOTO OKAWAKI, KAZUO MATSUURA, ICHIRO NAGAMINE, TAKUHIRO IKEDA, \\ MASAHIRO OHARA and YOICHI HAMAI
}

Department of Surgical Oncology, Research Institute for Radiation Biology and Medicine, Hiroshima University, Kasumi 1-2-3, Minami-ku, Hiroshima 734-8553, Japan

Received September 26, 2005; Accepted November 23, 2005

\begin{abstract}
Immunological parameters were measured in order to elucidate a postoperative immunosuppression mechanism in transthoracic esophagectomy for patients with esophageal cancer. Moreover, lymphokine-activated killer (LAK) cells were transferred just after the surgery to overcome the postoperative immunosuppression. Fifteen consecutive patients who underwent transthoracic esophagectomy were subjected to the postoperative measurement of immunological parameters. Ten patients who underwent open cholecystectomy served as controls. Heparinized venous blood was obtained pre- and postoperatively, and serum levels of cytokines IL-6 and IL-10 and immunosuppressive acidic protein (IAP) were measured. Peripheral blood lymphocytes were harvested and analyzed by flow cytometry for phenotype detection and by a mixed lymphocyte reaction for detecting concanavalin (Con)-A-induced or -non-induced suppressor activity. Another 29 consecutive patients who underwent transthoracic esophagectomy were randomly enrolled in a postoperative immunotherapy trial either with or without lymphokine-
\end{abstract}

Correspondence to: Dr Yoshiyuki Yamaguchi, Department of Surgical Oncology, Research Institute for Radiation Biology and Medicine, Hiroshima University, Kasumi 1-2-3, Minami-Ku, Hiroshima 734-8553, Japan

E-mail: shogo@hiroshima-u.ac.jp

Abbreviations: AIT, adoptive immunotherapy; CARS, compensatory anti-inflammatory response syndrome; $\mathrm{CD}$, cluster of differentiation; Con-A, concanavalin-A; FITC, fluorescein isothiocyanate; IAP, immunosuppressive acidic protein; IL, interleukin; LAK, lymphokineactivated killer; MLR, mixed lymphocyte reaction; PBMC, peripheral blood mononuclear cell; PE, phycoerythrin; SIRS, systemic inflammatory response syndrome; TIL, tumor-infiltrating lymphocyte; TNF, tumor necrosis factor; T-reg, regulatory $\mathrm{T}$ cell

Key words: postoperative immunosuppression, compensatory antiinflammatory response syndrome, esophageal cancer, adoptive immunotherapy, lymphokine-activated killer cells activated killer cells. It was found that, in the esophagectomy group, IL-6 and IL-10 increased postoperatively and peaked on day 1 , followed by an increase in IAP, peaked again on day 4 , with a profound decrease in helper and cytotoxic T-cell subsets, followed by increases in Con-A-induced (on day 7 or later) and spontaneous (on day 10) suppressor activities. These changes were minimal in the cholecystectomy group. LAK cell transfer restored the postoperative decrease in the helper and cytotoxic T-cell population, and there was a trend of reduction for postoperative remote infection such as pneumonia and surgical site infection in the LAK therapy group. Taken together, we would like to propose the existence of a postoperative immunosuppression cascade consisting of increases in cytokines and immunosuppressive proteins, decreases in helper and cytotoxic T-cell populations, and the development of suppressor T-cell activities in surgery for esophageal cancer. Postoperative adoptive transfer of LAK cells may be a novel clinical application in surgery for esophageal cancer as a means of treating this postoperative immunosuppressive condition that may be identical to the status of compensatory anti-inflammatory response syndrome (CARS).

\section{Introduction}

Major thoraco-abdominal surgery, as represented by transthoracic esophagectomy, causes profound postoperative surgical stress, which can stimulate the production of pro-inflammatory cytokines, including TNF, IL-1 and IL-6, by immunocompetent cells (1). This condition, based on hypercytokinemia, was defined in 1991 through the consensus conference of the American College of Chest Physicians/Society of Critical Care Medicine (ACCP/SCCM), as systemic inflammatory response syndrome (SIRS) (2). On the other hand, an antiinflammatory response is subsequently triggered by SIRS. This response is designated as compensatory anti-inflammatory response syndrome (CARS) (3). The anti-inflammatory cytokine IL-10 is a representative mediator in CARS status (4). Postoperative host responses are therefore understood as being a balance of SIRS and CARS, but they have not been 
fully explored in surgery for esophageal cancer. Moreover, an imbalance between these dual immune responses, with an overwhelming release of pro- or anti-inflammatory cytokines, seems to be responsible for organ dysfunction and increased susceptibility to infections (5). Medical regulation of SIRS and CARS has been conducted to improve these adverse effects, but the most desirable means of regulation remains under investigation (6-11).

The discovery and molecular cloning of the crucial lymphocyte growth factor, interleukin-2 (IL-2), has facilitated the clinical application of adoptive immunotherapy (AIT) for cancer using autologous lymphocytes activated in vitro with IL-2 (12). We have carried out ex vivo cell therapy for cancer treatment using activated autologous lymphocytes, including lymphokine-activated killer (LAK) cells, tumor-infiltrating lymphocytes (TILs), and tumor-sensitized lymphocytes, but tumor responses are limited with regard to quality of life in locoregional administration for malignant effusion from gastrointestinal cancers (13). Ueda et al have reported an efficacy of AIT using LAK cells for metastatic esophageal cancer (14). The clinical trials using postoperative LAK cell transfer have demonstrated survival benefits in hepatocellular carcinoma (15) and lung cancer (16). However, the effects of AIT using LAK cells for postoperative stress status, SIRS and CARS have not yet been demonstrated.

In the present study, we explored the postoperative immunosuppression cascade in esophageal cancer surgery. Moreover, we conducted postoperative LAK therapy for patients with esophageal cancer and found that this therapy may be a possible therapeutic application for the postoperative immunosuppressive condition, CARS.

\section{Materials and methods}

Patients. Fifteen consecutive patients with histologically proven esophageal squamous cell carcinoma who underwent transthoracic esophagectomy were subjected to postoperative immunosuppression measurements, and 10 patients with open cholecystectomy served as controls. Another 29 consecutive patients with esophageal cancer were enrolled in the adjuvant LAK therapy study after sufficient written informed consent. The protocol was approved by the institutional review board. The patients were randomly assigned to either the standard therapy group or the LAK therapy group.

Collection of blood samples and lymphocytes. Heparinized venous blood was obtained from patients and healthy volunteers, and buffy coat and plasma were immediately separated by centrifugation $(2,000 \mathrm{rpm}, 30 \mathrm{~min})$. The supernatant was subjected to measurements of cytokines and immunosuppressive acidic protein (IAP). The buffy coat was resuspended in RPMI-1640 medium, and the suspension was layered on Ficoll-Conray. Peripheral blood mononuclear cells (PBMCs) were isolated by gradient centrifugation $(2,000 \mathrm{rpm}$, $30 \mathrm{~min}$ ), washed twice, and resuspended in the medium containing $2 \% \mathrm{AB}$ serum at a density of $1 \times 10^{6} / \mathrm{ml}$.

Cytokines and acute inflammatory proteins. Collected plasma samples were subjected to the measurement for IL-6, IL-10 and immunosuppressive acidic protein (IAP). IL-6 and IL-10 were measured using an ELISA kit according to the manufacturer's instructions (R\&D Systems, Minneapolis, MN). IAP was measured by the SRL Co., Tokyo.

Flow cytometry. Fifty microliters each of the lymphocyte suspension $\left(5 \times 10^{5}\right)$ were stained with antibodies, washed, and then analyzed on a Cytoron (Ortho Diagnostic Systems, USA). The antibodies used were fluorescein isothiocyanate (FITC)-labeled anti-CD4 and-CD8 antibodies, phycoerythrin (PE)-labeled anti-CD45RA and -CD11b antibodies. All antibodies used were purchased from Becton-Dickinson, San Diego, CA.

Suppressor activity. A one-way mixed lymphocyte reaction (MLR) was performed as described in detail elsewhere (17). In brief, PBMCs were stimulated with 0 or $10 \mu \mathrm{g} / \mathrm{ml}$ concanavalin-A (Con-A, Boehringer, Germany) for $24 \mathrm{~h}$ at $37^{\circ} \mathrm{C}$. Cells were treated with $50 \mu \mathrm{g} / \mathrm{ml}$ mitomycin-C for $1 \mathrm{~h}$ at $37^{\circ} \mathrm{C}$, washed 3 times, and resuspended in the medium as effector cells $\left(5 \times 10^{5} / \mathrm{ml}\right)$. Responder PBMCs $\left(5 \times 10^{5} / \mathrm{ml}\right)$ were collected from healthy subjects. Effector and responder cells (1:1) were co-cultured in RPMI-1640 medium containing 2\% AB serum for 4 days at $37^{\circ} \mathrm{C}$ in the presence of $15 \mu \mathrm{g} / \mathrm{ml}$ phytohemagglutinin (Difco, USA). Cells were pulsed with $5 \mu \mathrm{Ci} / \mathrm{ml}{ }^{3} \mathrm{H}-$ thymidine and incubated for another $8 \mathrm{~h}$. Cells were harvested, and radioactivity was measured. Suppressor activity (SA) was calculated using the following formula: SA $(\%)=$ $\{1$ - MLR (cpm)/responder cells alone (cpm) $\}$ x 100 .

LAK cell generation and postoperative transfer. Plasmapheresis was performed using Haemonetics V30 (Haemonetics Corp., Braintree, MA) to harvest patients' white blood cells (WBCs) 2 weeks and 1 week before surgery. PBMCs were collected from WBCs by centrifugation. LAK cells were generated by culturing PBMCs $\left(10^{6} / \mathrm{ml}\right)$ for 2 weeks in RPMI-1640 medium containing $2 \%$ autologous serum and $400 \mathrm{U} / \mathrm{ml}$ IL-2 (Sionogi, Tokyo) supplemented with $2 \mathrm{mM}$ l-glutamine, $100 \mathrm{U} / \mathrm{ml}$ penicillin and $100 \mu \mathrm{g} / \mathrm{ml}$ streptomycin. The culture medium was half-changed with fresh medium containing IL-2 every 3-4 days. LAK cells ( $1-3 \times 10^{9}$ cells) were washed 3 times by saline, filtered through $200 \mu \mathrm{m}$ mesh, resuspended in $100 \mathrm{ml}$ saline, and administered intravenously twice a week (up to 6 times), postoperatively. Bacterial and endotoxin examinations were made 3 days before and on the day of administration.

Statistical analysis. Statistical analysis was conducted by the $\chi^{2}$ test or Student's t-test using StatView software (Version 5) on a Macintosh computer. All values are presented as mean \pm standard deviation, and $\mathrm{p}<0.05$ was defined as statistically significant.

\section{Results}

Patients for postoperative measurements of immunological parameters. The esophagectomy (EG) group included 15 patients consisting of 11 men and 4 women, with a mean age of 58 years (Table I). In the cholecystectomy (CC) group, there were 3 men and 7 women whose mean age was 55 . There was a significant difference between the EG and CC 
Table I. Patients for postoperative measurements of immunological parameters.

\begin{tabular}{lcc}
\hline & \multicolumn{2}{c}{ Group } \\
\cline { 2 - 3 } Categories & Cholecystectomy & Esophagectomy \\
\hline Gender & 3 & 11 \\
$\quad$ Male & 7 & 4 \\
Female & $55 \pm 11$ & $58 \pm 10$ \\
Age (mean \pm SD) & & \\
Operation time & $97 \pm 17$ & $379 \pm 75$ \\
(min, mean \pm SD) & $181 \pm 102$ & $570 \pm 210$ \\
Blood loss & & \\
$(\mathrm{g}$, mean \pm SD) & &
\end{tabular}
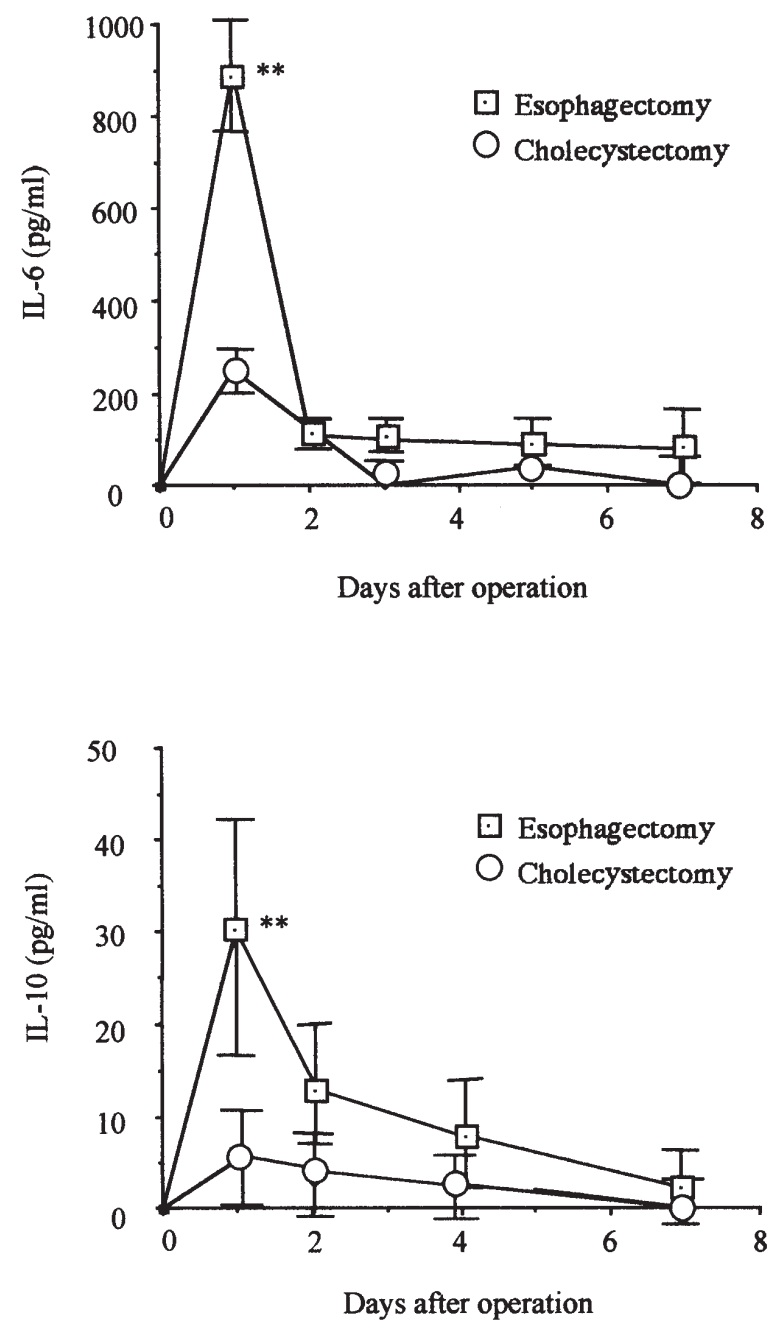

Figure 1. Postoperative changes in serum IL-6 and IL-10. Serum samples were postoperatively collected from patients who underwent transthoracic esophagectomy or open cholecystectomy, and IL-6 and IL-10 levels were measured. A significant difference, ${ }^{* *} \mathrm{p}<0.01$.

groups with regard to gender $(\mathrm{p}<0.05)$. Operative time and blood loss were $378 \mathrm{~min}$ and $570 \mathrm{~g}$ for the EG group, and 97 min and $181 \mathrm{~g}$ for the CC group, respectively. There were significant differences in these values $(\mathrm{p}<0.05)$.

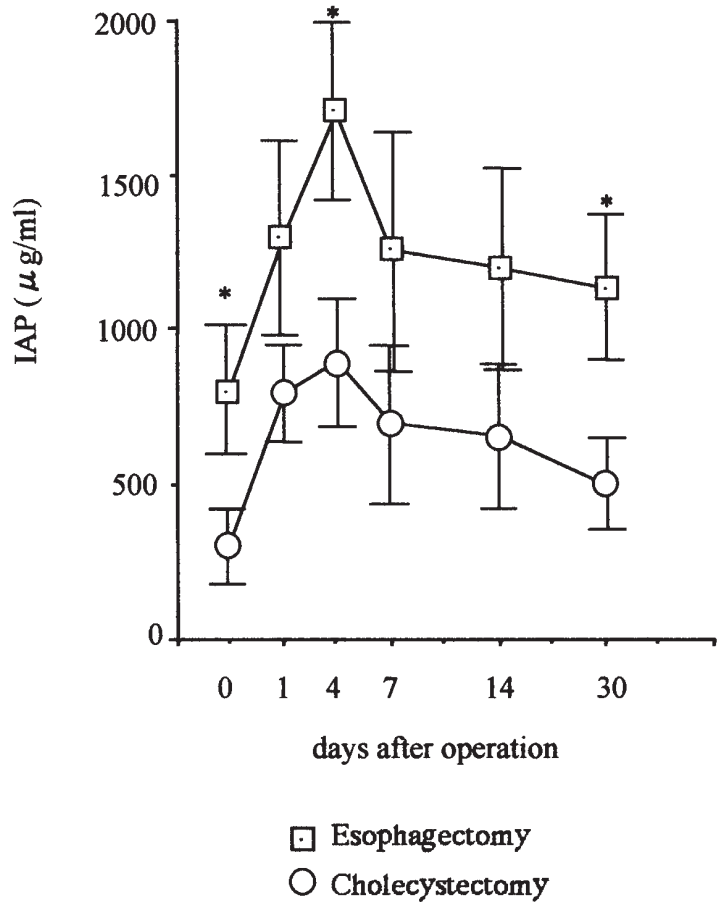

Figure 2. Postoperative changes in serum IAP. Serum samples were postoperatively collected from patients who underwent transthoracic esophagectomy or open cholecystectomy, and IAP levels were measured. Significant differences, ${ }^{*} \mathrm{p}<0.05$

Postoperative changes in serum IL-6 and IL-10 in patients with esophageal cancer. Postoperative cytokine levels were investigated (Fig. 1). Serum levels of IL-6 increased postoperatively, peaked on day 1 , and then decreased. Serum levels of IL-10 fluctuated similarly with those of IL-6. Significant increases of IL- 6 and IL-10 were observed on day 1 in the EG group compared with the $\mathrm{CC}$ group $(\mathrm{p}<0.01)$.

Postoperative changes in serum IAP. Postoperative changes in IAP, an acute-phase reactant protein, were investigated (Fig. 2). Serum levels of IAP increased postoperatively, peaked on day 4 , and then decreased. Significant increases in IAP were observed before surgery, on day 4 , and still on day 30 in the EG group compared with the CC group $(\mathrm{p}<0.05)$.

Postoperative changes in helper and cytotoxic $T$ cell population. Postoperative changes in functional lymphocyte subsets, including the $\mathrm{CD}^{+}{ }^{+} \mathrm{CD} 45 \mathrm{RA}^{-}$helper subset and the CD8 ${ }^{+} \mathrm{CD} 11 \mathrm{~b}^{-}$cytotoxic T-cell subset, were investigated (Fig. 3). Changes in the helper and cytotoxic T-cell subsets were minimal in the CC group. In the EG group, however, levels of the helper subset significantly decreased compared with those in the CC group on day 1, continuing through day 14, and recovering, to a lesser extent, but still remaining at low levels on day $30(\mathrm{p}<0.05)$. The changes in the cytotoxic T-cell subset in the EG group were very similar to those of the helper subset.

Postoperative changes in suppressor activity. Con-A-induced and -non-induced (spontaneous) suppressor activities were 

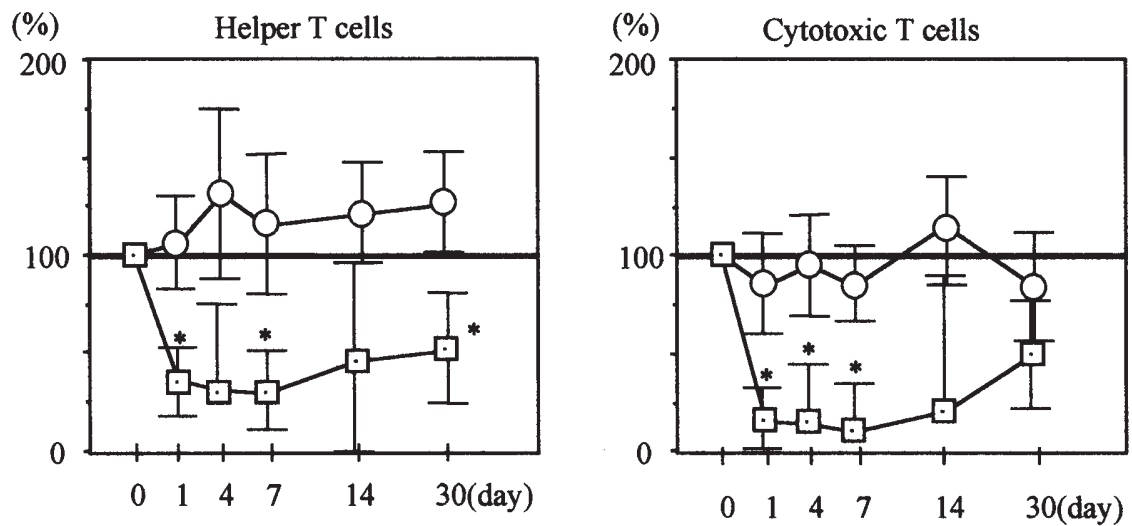

Days after operation

\section{Esophagectomy \\ Cholecystectomy}

Figure 3. Postoperative changes in helper and cytotoxic T-cell subsets. PBMCs were postoperatively collected from patients who underwent transthoracic esophagectomy or open cholecystectomy, and helper and cytotoxic T-cell subsets were measured by flow cytometry. Significant differences, ${ }^{*} \mathrm{p}<0.05$.

Con-A-induced

(\%) suppressor cell activity

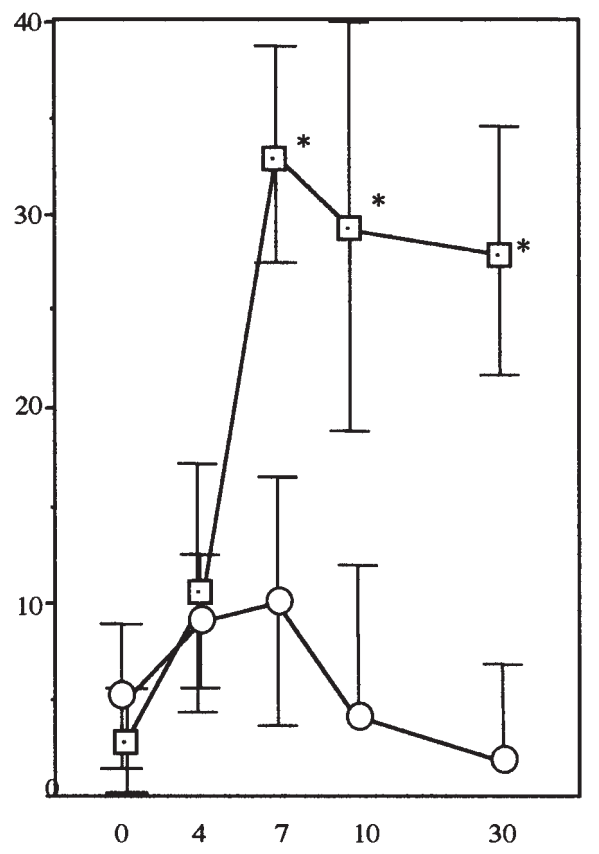

Spontaneous

(\%) suppressor cell activity

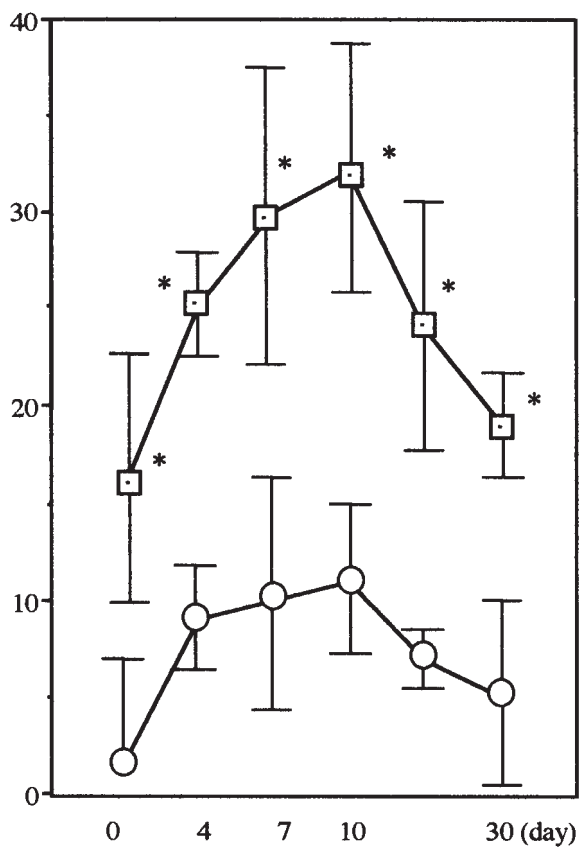

Days after operation

\section{$\square$ Esophagectomy \\ Cholecystectomy}

Figure 4. Postoperative changes in suppressor activities. PBMCs were postoperatively collected from patients who underwent transthoracic esophagectomy or open cholecystectomy, and suppressor activities were measured as described in Materials and methods. Significant differences, ${ }^{*} \mathrm{p}<0.05$.

investigated (Fig. 4). Con-A-induced suppressor activity significantly increased in the EG group, peaked on day 7 , then gradually decreased but still remained high on day 30 $(\mathrm{p}<0.05)$. Con-A-non-induced spontaneous suppressor 
Table II. Esophageal cancer patients received postoperative adjuvant LAK therapy.

\begin{tabular}{lcc}
\hline & \multicolumn{2}{c}{ LAK therapy } \\
\cline { 2 - 3 } & $(-), \mathrm{n}=15$ & $(+), \mathrm{n}=14$ \\
\hline Gender & 13 & 14 \\
$\quad$ Male & 2 & 0 \\
Female & $47-77(61.8)$ & 1 \\
Age, range (mean) & & 1 \\
Stage & 4 & 2 \\
0 & 0 & 6 \\
1 & 1 & 4 \\
2 & 6 & \\
3 & 4 & \\
4 & - & $3-6(4)$ \\
LAK cell numder & & \\
(range, median) & & \\
No. of transfer & - & \\
(range, median) & &
\end{tabular}

activity also increased significantly in the EG group, but peaked on day 10 , and decreased thereafter $(\mathrm{p}<0.05)$. These changes were minimal in the $\mathrm{CC}$ group.

Patients with esophageal cancer who received postoperative adjuvant LAK therapy. Twenty-nine patients who underwent transthoracic esophagectomy were randomly treated postoperatively with or without LAK cell transfer. Patient characteristics are shown in Table II. There were no significant differences between LAK (+) and (-) groups in terms of gender, age or tumor stage. LAK cells were transferred safely postoperatively approximately four times with a total dose of $4.5 \times 10^{9}$ cells (median).
Table III. Postoperative infections after esophagectomy with or without LAK therapy.

\begin{tabular}{lcc}
\hline & \multicolumn{2}{c}{ LAK } \\
\cline { 2 - 3 } Infection & $(-), \mathrm{n}=15$ & $(+), \mathrm{n}=14$ \\
\hline$(-)$ & 10 & 12 \\
$(+)$ & 5 & 2 \\
Pulmonary & 3 & 2 \\
Wound & 2 & 0 \\
\hline
\end{tabular}

Patients who underwent transthoracic esophagectomy were treated either with or without postoperative LAK cell transfer. The incidence of postoperative pneumonia and wound infections was evaluated. The statistical difference between the LAK(+) and LAK(-) groups was $\mathrm{p}=0.09$.

Effects of postoperative LAK therapy on changes in helper and cytotoxic T-cell subsets. Effects of LAK cell transfer on the postoperative changes in helper and cytotoxic $\mathrm{T}$ cell subsets were studied (Fig. 5). Levels of the helper subset decreased postoperatively, as mentioned above for the LAK(-) group. This decrease in levels of the helper subset was almost abrogated with postoperative LAK cell transfer. As for the cytotoxic T-cell subset, postoperative LAK therapy restored the decrease in the subset, similarly to the effects of the helper subset. Significant differences were observed between LAK(-) and $\mathrm{LAK}(+)$ groups with regard to the percentage of postoperative helper T-cell and cytotoxic T-cell populations $(\mathrm{p}<0.05)$.

Postoperative infection after esophagectomy with or without LAK therapy. Postoperative pulmonary and wound infections were evaluated (Table III). In the LAK(-) group, 3 and 2 of 15 patients developed pneumonia and wound infection, respectively. In contrast, only 2 of 14 patients developed pneumonia in the $\mathrm{LAK}(+)$ group, and no wound infection was
(\%)

\section{Helper $\mathbf{T}$ cell}

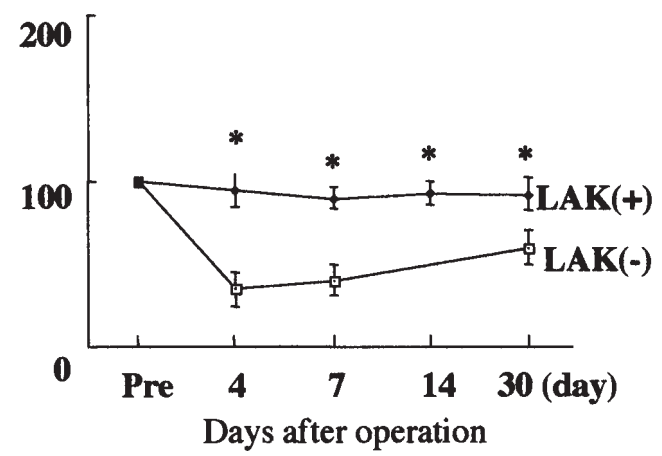

\section{Cytotoxic T cell}

(\%)

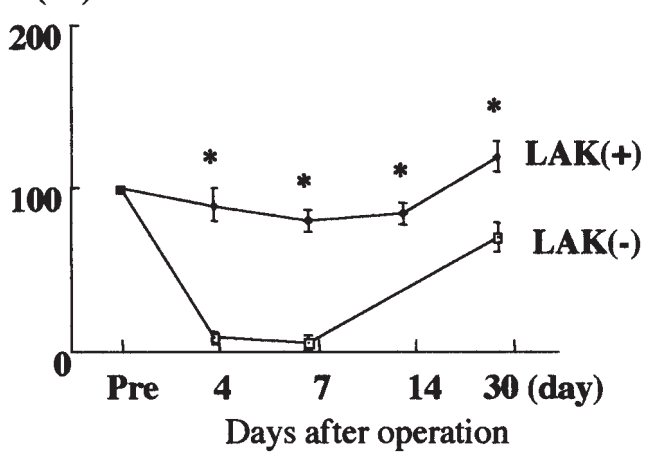

Figure 5. Effects of postoperative LAK therapy on changes in helper and cytotoxic T-cell subsets. LAK cells were prepared preoperatively. Patients who underwent transthoracic esophagectomy were treated either with or without postoperative LAK cell transfer. PBMCs were collected postoperatively, and helper and cytotoxic T cell subsets were measured in each group by flow cytometry. Significant differences, ${ }^{*} \mathrm{p}<0.05$. 


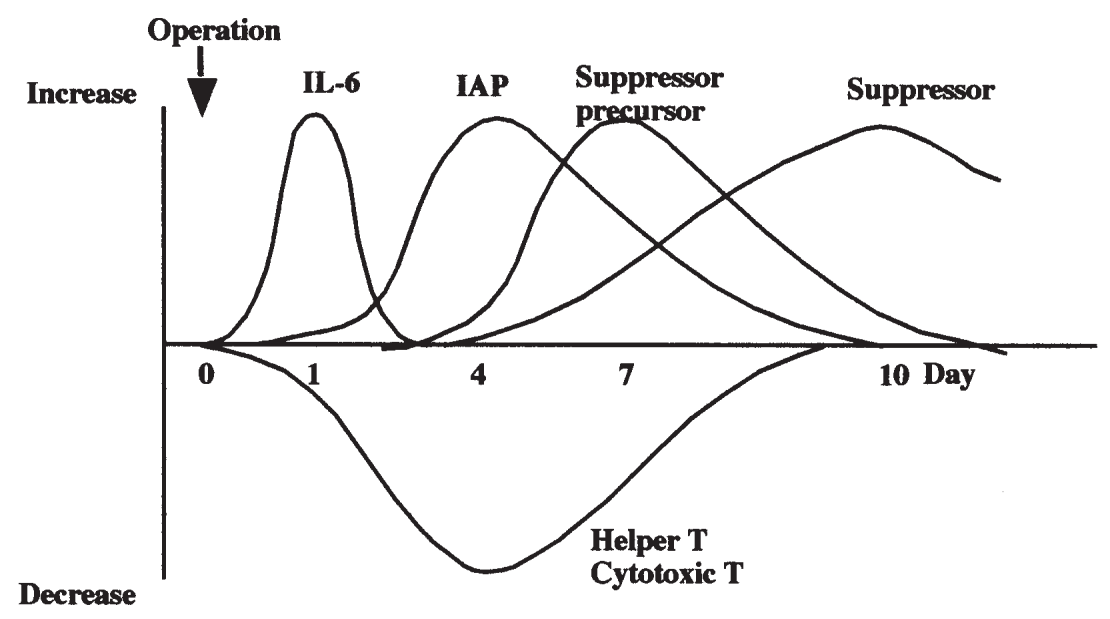

Figure 6. A proposal regarding the postoperative immunosuppression cascade. A postoperative immunosuppression cascade appears to exist that starts from increases in inflammatory cytokines, followed by increases in immunosuppressive proteins, decreases in helper and cytotoxic T-cell populations, and the development of suppressor cell activities, all of which contribute to the emergence of CARS in surgery for esophageal cancer.

observed. There was a trend of reductive effects on infections in the LAK $(+)$ groups $(\mathrm{p}=0.09)$.

\section{Discussion}

We investigated postoperative changes in immunological parameters in order to elucidate the influences of surgical stress and host responses after transthoracic esophagectomy. It was found that levels of proinflammatory cytokine IL- 6 and antiinflammatory cytokine IL-10 increased postoperatively and peaked on day 1 , followed by an increase in acute-phase reactant protein IAP, peaked on day 4 , with a profound decrease in levels of helper and cytotoxic T-cell subsets, followed by increases in Con-A-induced and spontaneous suppressor activities. IL-6 has been reported to induce acute-phase reactant proteins like C-reactive protein and $\alpha 1$-acid glycoprotein (18). IAP has been reported to be a member of the $\alpha 1$-acid glycoprotein family (19). IAP also has been demonstrated to down-modulate CD4 molecules on the lymphocyte surface, leading to the establishment of cancer-associated immunodepression, and to induce suppressor-inducer cells (20). Con-A-induced suppressor cell activity has been reported to indicate the presence of suppressor precursor cells that mature in response to stimulation with suppressor inducer cells (17). Based on the above, we propose the existence of a postoperative immunosuppression cascade consisting of increases of cytokines, immunosuppressive proteins, decreases in helper and cytotoxic T-cell populations, and the development of suppressor T-cells (Fig. 6). All of these are triggered by the increase in inflammatory cytokines that induce humoral and cellular suppressive components.

In our postoperative immunosuppression cascade, suppressor cells are finally activated and differentiated. Recently, Sakaguchi et al (21) reported the existence of $\mathrm{CD} 4{ }^{+} \mathrm{CD} 25^{+}$new suppressor cells, designated as regulatory $\mathrm{T}$ (T-reg) cells. T-reg cells have been demonstrated to be involved in auto-immunity, tumor immunity, chronic infection and infertility. Murphy et al (22) have reported in a murine model that T-reg cells are involved in the suppression of innate immunity after the stress of injury. Although we did not fractionate lymphocytes by using CD4 antigen in the MLR experiments, the Con-A-induced or spontaneous suppressor activities described herein may include, to some extent, $\mathrm{CD} 4{ }^{+} \mathrm{CD} 25^{+} \mathrm{T}$-reg cell activity, as these suppressor activities have been shown to reside in $\mathrm{CD} 4{ }^{+} \mathrm{CD} 62 \mathrm{~L}^{+}$cells (23). Moreover, it has been reported that the development of T-reg cells requires transforming growth factor (TGF)- $\beta$ (24), and we have demonstrated TGF- $\beta$ production by $C D 62 \mathrm{~L}^{+}$ cells (23). Elias et al have reported the existence of an IL-6TGF- $\beta$ regulation system in a human fibroblast model (25). These results suggest that T-reg cells may also be involved in the postoperative immunosuppression cascade in the human system. This hypothesis remains to be tested further.

The postoperative immunosuppression cascade described herein may be matched with the compensatory antiinflammatory response syndrome (CARS). The CARS is a reciprocal situation triggered by SIRS after surgical stress $(3,4)$. The CARS can cause remote infections, including pneumonia, based on profound immunodepression, where IL-10 plays an important role (5). IL-10 is a T-helper type 2 cytokine (11). Through insights into the pathophysiological mechanisms of SIRS and CARS, strategies for the use of T-helper type 1 cytokines of G-CSF (8), GM-CSF (9), IFN- $\gamma$ (10) and IL-12 (11), have been studied with regard to the treatment of CARS, but the clinical benefits remain under investigation. In our study, CARS was thought of as a depression of functional lymphocytes, including helper $\mathrm{T}$ cells and cytotoxic $\mathrm{T}$ cells. This perspective may indicate that adoptive transfer of activated lymphocytes, for example LAK cells, is of use. It has been reported that IL-2-activated peripheral blood LAK cells consist of $\mathrm{CD}^{+}$and CD8 cells as well as NK cells $(26,27)$. Moreover, we have system for easily expanding LAK cells in our laboratory (13). Our preliminary clinical investigation showed that postoperative LAK cell transfer restores the decrease in helper and cytotoxic T-cell populations. Moreover, there has been a trend of reduction for postoperative remote infection and surgical site infection in the LAK therapy group. These results suggest that postoperative 
adoptive transfer of LAK cells may be a novel clinical application for the treatment of CARS. A large clinical trial is now in progress for clarifying the anti-CARS effects of LAK therapy in patients with esophageal cancer.

\section{Acknowledgements}

We would like to thank Miss Y. Nakatani for her special help with the tissue culture.

\section{References}

1. Dinarello CA: Proinflammatory cytokines. Chest 118: 503-508 2000.

2. Definitions for sepsis and organ failure and guidelines for the use of innovative therapies in sepsis. American College of Chest Physicians/Society of Critical Care Medicine Consensus Conference. Crit Care Med 20: 864-874, 1992.

3. Bone RC: Sir Isaac Newton, sepsis, SIRS and CARS. Crit Care Med 24: 1125-1128, 1996

4. Hensler T, Sauerland S, Bouillon B, Raum M, Rixen D, Helling HJ, Andermahr J and Neugebauer EA: Association between injury pattern of patients with multiple injuries and circulating levels of soluble tumor necrosis factor receptors, interleukin-6, and interleukin-10 and polymorphonuclear neutrophil elastase. J Trauma 52: 962-970, 2002.

5. Keel M and Trentz O: Pathophysiology of polytrauma. Injury 36: 691-709, 2005.

6. Fisher CJ Jr, Agosti JM, Opal SM, Lowry SF, Balk RA, Sadoff JC, Abraham E, Schein RM and Benjamin E: Treatment of septic shock with the tumor necrosis factor receptor $\mathrm{Fc}$ fusion protein. Soluble TNF Recetpor Study Group. N Eng J Med 334: 1697-1702, 1996

7. Lyons A, Goebel A, Mannick JA and Lederer JA: Protective effects of early interleukin 10 antagonism on injury-induced immune dysfunction. Arch Surg 134: 1317-1323, 1999.

8. Gross-Weege W, Weiss M, Schneider M, Wenning M, Harms B, Dumon K, Ohmann C and Roher HD: Safety of a low-dosage Filgrastim (rhG-CSF) treatment in non-neutropenic surgical intensive care patients with an inflammatory process. Intensive Care Med 23: 16-22, 1997.

9. Fanning NF, Kell MR, Shorten GD, Kirwan WO, BouchierHayes D, Cotter TG and Redmond HP: Circulating granulocyte macrophage colony-stimulating factor in plasma of patients with the systemic inflammatory response syndrome delays neutrophil apoptosis through inhibition of spontaneous reactive oxygen species generation. Shock 11: 167-174, 1999.

10. Kox WJ, Bone RC, Krausch D, Docke WD, Kox SN, Wauer H, Egerer K, Querner S, Asadullah K, von Baehr R and Volk HD: Interferon gamma-1b in the treatment of compensatory antiinflammatory response syndrome: a new approach: proof of principle. Arch Intern Med 157: 389-393, 1997.

11. O'Sullivan ST, Lederer JA, Horgan AF, Chin DH, Mannick JA and Rodrick ML: Major injury leads to predominance of the T helper-2 lymphocyte phenotype and diminished interleukin-12 production associated with decreased resistance to infection. Ann Surg 222: 482-490, 1995.

12. Rosenberg SA, Lotze MT, Muul LM, Leitman S, Chang AE, Ettinghausen SE, Matory YL, Skibber JM, Shiloni E, Vetto JT, Seipp CA, Simpson C and Reichert CM: Observations on the systemic administration of autologous lymphokine-activated killer cells and recombinant interleukin-2 to patients with metastatic cancer. N Eng J Med 313: 1485-1492, 1985.
13. Yamaguchi Y, Ohshita A, Kawabuchi Y, Ohta K, Shuimizu K, Minami K, Hihara J, Miyahara E and Toge T: Adoptive immunotherapy of cancer using activated autologous lymphocytes: current status and new strategies. Human Cell 16: 183-189, 2003.

14. Ueda Y, Yamagishi H, Tanioka Y, Fujiwara H, Fuji N, Itoh T, Fujiki H, Yoshimura T and Oka T: Clinical application of adoptive immunotherapy and IL-2 for the treatment of advanced digestive tract cancer. Hepatogastroenterology 46: 1274-1279, 1999.

15. Takayama T, Sekine T, Makuuchi M, Yamasaki S, Kosuge T, Yamamoto J, Shimada K, Sakamoto M, Hirohashi S, Ohashi Y and Kakizoe T: Adoptive immunotherapy to lower postsurgical recurrence rates of hepatocellular carcinoma: a randomised trial. Lancet 356: 802-807, 2000.

16. Kimura $\mathrm{H}$ and Yamaguchi $\mathrm{Y}$ : A phase III randomized study of interleukin-2 lymphokine-activated killer cell immunotherapy combined with chemotherapy or radiotherapy after curative or non-curative resection of primary lung carcinoma. Cancer 80: 42-49, 1997.

17. Toge T, Hamamoto S, Itagaki E, Yajima K, Tanada M, Nakane H, Kohno H, Nakanishi K and Hattori T: Concanavalin A-induced and spontaneous suppressor cell activities in peripheral blood lymphocytes and spleen cells from gastric cancer patients. Cancer 52: 1624-1631, 1983 .

18. Banks RE, Forbes MA, Storr M, Higginson J, Thompson D, Raynes J, Illingworth JM, Perren TJ, Selby PJ and Whicher JT: The acute phase protein response in patients receiving subcutaneous IL-6. Clin Exp Immunol 102: 217-223, 1995.

19. Shibata Y, Tamura K and Ishida N: Cultured human monocytes, granulocytes and a monoblastoid cell line (THP-1) synthesize and secrete immunosuppressive acidic protein (a type of alpha 1-acid glycoprotein). Microbiol Immunol 28: 99-111, 1984.

20. Yamaguchi Y, Miyahara E, Funakoshi M, Takashima I, Kawami H, Sato Y and Toge T: Modulation of CD4 antigen expression on the lymphocyte surface by immunosuppressive acidic protein in cancer patients. Oncology 52: 1-6, 1995.

21. Sakaguchi S, Sakaguchi N, Asano M, Itoh M and Toda M: Immunologic self-tolerance maintained by activated $\mathrm{T}$ cells expressing IL-2 receptor alpha-chains (CD25). Breakdown of single mechanism of self-tolerance causes various autoimmune disease. J Immunol 155: 1151-1164, 1995.

22. Murphy TJ, Choileain NN, Zang Y, Mannick JA and Lederer JA: $\mathrm{CD} 4^{+} \mathrm{CD} 25^{+}$regulatory $\mathrm{T}$ cells control innate immune reactivity after injury. J Immunol 174: 2957-2963, 2005.

23. Noma K, Yamaguchi Y, Okita R, Matsuura K and Toge T: The spleen plays an immunosuppressive role in patients with gastric cancer: involvement of $\mathrm{CD}_{2} \mathrm{~L}^{+}$cells and TGF-beta. Anti-cancer Res 25: 643-649, 2005 .

24. Fantini MC, Becker C, Monteleone G, Pallone F, Galle PR and Neurath MF: Cutting edge: TGF-beta induces a regulatory phenotype in $\mathrm{CD} 4^{+} \mathrm{CD} 25^{-} \mathrm{T}$ cells through Foxp3 induction and down-regulation of Smad7. J Immunol 172: 5149-5153, 2004.

25. Elias JA, Lentz V and Cummings PJ: Transforming growth factor-beta regulation of IL-6 production by unstimulated and IL-1-stimulated human fibroblasts. J Immunol 146: 3437-3443, 1991.

26. Damle NK, Doyle LV and Bradley EC: Interleukin 2-activated human killer cells are derived from phenotypically heterogeneous precursors. J Immunol 137: 2814-2822, 1986.

27. Sekine T, Shiraiwa H, Yamazaki T, Tobisu K and Kakizoe T: A feasible method for expansion of peripheral blood lymphocytes by culture with immobilized anti-CD3 monoclonal antibody and interleukin-2 for use in adoptive immunotherapy of cancer patients. Biomed Pharmacother 47: 73-78, 1993. 